International Journal of Scholarly Papers for Media and Society Research

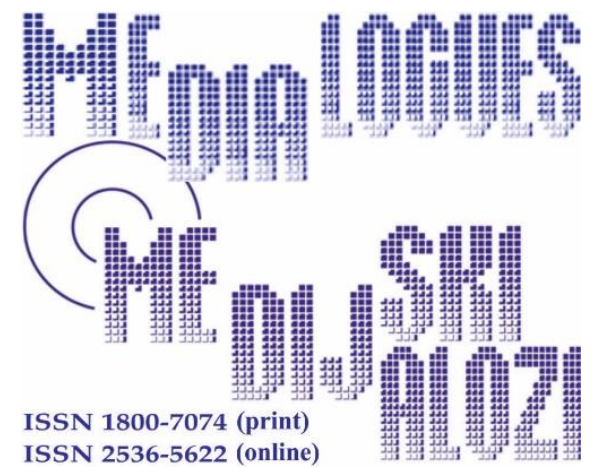

Tepavcevic, M. (2019), „Linguistic Specificities of Media Headline Discourse - in the Case of Montenegrin Newspapers)“, Media Dialogues / Medijski dijalozi, Vol. 14, No. 2, pp. 75-87.

\title{
Linguistic Specificities of Media Headline Discourse - in the Case of Montenegrin Newspapers
}

\author{
Assistant Professor MIODARKA TEPAVCEVIC, \\ University of Montenegro, Faculty of Philology, \\ Niksic, Montenegro
}

\begin{tabular}{|c|c|l|}
\hline $\boldsymbol{A} \boldsymbol{R} \boldsymbol{T} \boldsymbol{I} \boldsymbol{C L} \boldsymbol{E}$ & Received: November 17,2021 / Revised from: December 18, 2021 \\
$\boldsymbol{I} \boldsymbol{N} \boldsymbol{F} \boldsymbol{O}$ & Accepted: January 18, 2021 / & Available online: April 15, 2021 \\
\hline $\boldsymbol{D O I}$ & doi.org/10.14254/1800-7074/14-2/5 \\
\hline
\end{tabular}

\section{ABSTRACT}

In this study, the author is dealing with the characteristics of Montenegrin media headline discourse, actually exploring the extent to which the headline discourse is sensationalist and negative. The analysis has included larger and more influential daily newspapers in Montenegro (,Pobjeda“ - pro-government, ,, Vijesti “ and „Dan“ - pro-opposition) over a period of one month. The paper is based on the assumption that mass media are a factor influencing the culture of a society, but they 
are also the product of the same culture and society. Given the number of sensationalist headlines published in the monitored newspapers, we recognize a confirmation of the hypotheses that the headline communication culture is at a lower level than expected, that most of these headlines occur in sections on interior politics and society, and that there are differences in preference for certain contents between headlines in Montenegrin daily newspapers.

KEYWORDS: Media Language, Montenegrin Newspapers, Headlines, communications.

„Same message, communicated through different types

of technical means for transmitting messages,

causes unequal effects,

meaning that the power of the message does not depend only on the content of the message

but also on the shape and structure

of the technical transmitter".

Susnjic, 1984, p. 89.

\section{INTRODUCTION}

Media discourse is a rich repository for diverse research, taking into account its specific lexicon, genre diversity, impact on other discourses, specific syntactic structures, media connection to social, socio-cultural and economic relations. The language used in the media discourse utilizes a wide range of rhetorical means on phonological, syntactic, lexical, semantic, pragmatic and textual level. The media represent a general reference to information, knowledge and public opinion. Thus, it does depend on the quality of democracy which kind of media system is established, which standards of quality the media generally realize, and at which level of media literacy the audience is. Of course, all these factors of media and communication culture reflect the democratic quality of life in a society. In various ways, media shape our aspirations and attitudes, and give us a deeper insight into the quality of life, so in the interpretation of social and cultural influence of the media great importance is given to media responsibility, control and self-control. In his latest study on media literacy, James Potter (2011, p. 7) argues that people get their meaning of life determined by the gradual influence of the media, meaning that the behavior, attitudes and emotions of the people will gradually be aligned with such determination.

When it comes to the relationship between the media and language, we notice that these constantly influence one another and that language is a significant factor in the differentiation of media. Language is not only a static factor of the media, but 
also their dynamic element. Language is where various aspects of power come to life, determining the interaction between people, and the media are seen as a game for power or a power game, which is why language is inextricably linked to the media and to power. Media language reflects the society in which it is created and the relationships in this society, but it also creates these relationships. The media have a certain social impact and receive a portion of public power. The power of the media raises the question of how to fight against media manipulation and bias.

It is a known fact that newspaper articles in the press, and to an even greater extent in the electronic media and multimedia, usually last for only a few seconds, one minute, an hour, a day, a week... depending on the news flow rate, on the freshness of the information, on the willingness of the "gate guardians" to let them through, on the time of appearance (issue publication) or the magazine/program in which they are published (Todorovic, 2013, p. 17). Therefore, the setting for manipulation is easily created if constant repetition of inaccurate and unverified information makes them sound like an official statement. There is a fine line between persuasion and manipulation, and it is necessary to set a limit so that the audience would not be forced to accept an opinion or adopt a behavior (Breton, 2000, p. 37). Informative function of the media thus grows into a function of social action, substantially shaping everyday life of human beings and their opinions (Udovicic, 2007, p. 41). The goal of manipulation is getting a profit, a part of the social power, or pandering to the authorities. Information disclosed by the media can be an integral part of manipulative techniques to which an individual is exposed, from distorting the portrayal of an event to hiding the real facts and truth.

Media discourse incorporates a number of language mechanisms that implicitly or explicitly convey political content, shape public politics, lay down the roles of the stakeholders and target groups, carry messages of identity, gather political support, and define objectives. Language is an instrument through which, unconsciously or strategically, given concepts are stressed, concealed, distorted or evaluated, making it a discourse tool of public politics with the function of persuasion and political legitimization. No matter which genre they belong to, the media are designed on the principle of monologue, with a strategy of persuasion, imposing views and suggestions to the addressees, which places the latter ones in a subordinate role. The words of the media are never randomly selected, are never "collected" in communication just like that, without a goal.

The words of the media always try to verbalize the idea that they carry, whatever the idea may be. In fact, "the medium is the message" (McLuhan, 1964, p. 15).

In this paper, we are going to deal with the characteristics of headline discourse in Montenegrin daily newspapers, actually exploring the extent to which the headline discourse is sensationalist and negative. The analysis included larger and more influential daily newspapers in Montenegro („Pobjeda“ - pro-government, „Vijesti“ and „Dan“ - pro-opposition) over a period of one month (May 1 to June 1, 2015). The 
study was initiated with the aim of determining how the media editorial boards relate to language in the headlines selected for the front pages. The starting assumption was that headlines, even those that would not be on the cover, and in particular those on the front page, are designed with special stylistic care, in order to attract but also to keep the readers who see them.

As each medium has a specific editorial policy and ways to portray events and occurrences, a research of themes and rhetoric in headline contents has been carried out. As part of the research, the following hypotheses were made:

- Texts in Montenegrin daily newspapers Pobjeda, Vijesti and Dan contain a proportionally large number of headlines bearing sensationalist and negative character, and the communication culture of the headlines is lower because of the sales and commercial reasons.

- There are significant differences in headlines of negative character in the texts of the Montenegrin dailies.

- Headlines of negative and inappropriate content mostly refer to interior politics and society.

\section{MEDIA PICTURE IN MONTENEGRO}

Media scene in Montenegro is pluralistic, which is to say that there are a number of media companies active in this small market. According to the official data of the Agency for Electronic Media from 2015, there are 21 TV channels, 55 radio stations, five daily newspapers and one weekly 1 in Montenegro. The only Montenegrin news agency is MINA, which is privately owned. Despite their growing popularity, there is no official comprehensive list of websites or electronic magazines. However, even with such a wide range of media, the challenges related to the financial sustainability and deep polarization limit the economic and political independence of the media sector from the state.

The legislative and institutional framework is inclusive and, for the most part, in line with international recommendations. It guarantees the right to free expression, media freedom and independence. Journalism is permeated by two systems of rules: legal and ethical. Multiplicity of media, no doubt, has consequences on their professionalism, on the status of journalism in Montenegro. The print media in Montenegro are generally "pro-government" and "pro-opposition". With the majority of its texts, the daily "Pobjeda" supports government politics with no critical distance towards the given themes. The so-called "opposition" media function on several variables, of which the basic two are - pro-Serbian viewpoint represented in the newspaper "Dan", aimed at citizens of Montenegro who still see Serbia and Montenegro as one nation and one country, and the so-called "anti-government" viewpoint, embodied in the daily newspaper "Vijesti", whose reporting is aimed at providing political sup- 
port to the opposition parties, which can be seen by analyzing the discourse used, as well as the treatment and evaluation of participants and events (Tasic, 2014) .

The constant growth of print media in Montenegro, on the one hand, and media efforts to acquire or retain the favor of readers, on the other, cause a competitive rivalry of the media. In this competition to win the favor of the audience, media companies are forced to follow the expectations of the target group and choose those events that they believe will attract the interest of the target audience. When it comes to the media in Montenegro, given the market circumstances, it is difficult to talk about economic independence of any media whatsoever. No media can survive only by mere commercial revenue from its audience. Montenegrin media usually are a mirror of the society, but often with a hidden reflection due to the socio-economic situation and complex political relations. Journalists constantly strive to subordinate the newsrooms to their own goals or to turn them into their public address stations. This is much more difficult to achieve if the media are economically independent. Journalism in Montenegrin society is often marked by political relations (and divisions). Based on this, a large part of the media, and some of them even quite clearly, are individually profiled.

\section{HEADLINE LANGUAGE}

Journalistic style differs from other functional styles in headlines, as well. Sometimes, it depends on these whether the text will be read. Thus, headlines are always in the prime place in the newspaper, with key words of expressive meaning. Also significant is the role of typeset graphics - size, design, color - serving to differentiate certain segments, such as section title, article heading, text headline, subheading within the text etc. (Tosovic, 2002, p. 249).

Textual linguistics considers that headlines constitute one of the strong positions of the text, regardless of their functional-stylistic affinities. The function of a newspaper headline is to attract the attention of the addressees, but also to direct them concisely, interestingly - to the main content of the article that is before them. It needs to include basic information about the content of the text, as well as to be in an effective, striking language. Therefore, a headline should fulfill the requirements of informativeness, expressiveness and economy. Headlines have conative, referential and expressive functions (Katnic-Bakarsic, 1999, p. 98), and which of these functions is dominant depends on the type of media, the text itself, or whether it is an informative, literary-journalistic or analytical text. It is often in the headlines that a change of the language function occurs, from referential and conative to poetic and expressive (Katnic-Bakarsic, 1999, p. 60). A headline - as an obligatory structural element of a newspaper article - with a communicative function to make distinctive a specific message in relation to a multitude of others, and then an epistemological function - to facilitate the understanding of the message, also has a metacommunicative function - to discover the intentions of communicators and clarify the position 
of a recipient in a communication situation, which is to say the extent to which it corresponds to the expectations of the communicators (Malovic, 2007, p. 141).

Headline functions are achieved through a different sentential or syntagmatic structure. They can be explicated by making comprehensive observations in the form of sentences, or emphasizing a single part. Newspaper headlines, as the most prominent element and an essential part of the text, actually the key place of the text in its central position, mediate between the author of the text and the reader. With its syntactic structure, discursive unity and polysemy, headlines of unusual contents are intended to attract attention and specify text information while highlighting relevance and attractiveness of the topic. If journalists want to emphasize some aspects or participants of the events, in the news these aspects will be in a prominent place in the headline or the subheading (Katnic-Bakarsic, 2012, p. 103). A headline in factual writing, both as a point and a bait, has to meet certain criteria, and above all, be informative, as well as attractive and interesting. Headlines of all kinds operate more strongly than texts and, in general, a reader will read more headlines than texts.

Schneider and Eslinger have set up five requirements that determine a good headline, which according to them: must contain a clear statement, must be a central expression of the text, must not falsify the text, must be fair, easy to understand and unambiguous, must excite curiosity of the readers (Rus-Mol and Zagorac-Kerser, 2005, p. 152). In the opinion of Slavica Perovic, a headline's value is reflected in the statement condensity and originality, elegance and wit of language, and avoidance to simultaneously slip into the language background, which is the ambiguity, except when one wants to. In addition, it is important not to abuse the language (Perovic, 2009, p. 61). Since a headline has the most difficult function, to communicate as much as possible as briefly as possible, while at the same time being attractive and drawing readers' attention, it first of all has to be exact, although only a summary.

\section{ANALYSIS}

In the period from May 1 to June 1, 2015, we have been analyzing important Montenegrin daily newspapers Pobjeda, Vijesti and Dan, which have a different editorial policy and ownership structure, and are therefore a distinctive indicator of political diversity in Montenegro. In the given period, out of the analyzed sample 1,250 titles - these daily newspapers have published 178 headlines with sensational and negative content. When it comes to sections, the majority of these headlines were in interior politics and society 99 („Dan“ - 12/14, „Vijesti“ - 31/32, „Pobjeda“ - 7/3), while 15 headlines were related to the world (,Dan“ - 8, „Vijesti“ - 1, „Pobjeda“ 6), and 11 to the crime \& accidents section („Dan“ - 4, „Vijesti“ - 6, „Pobjeda“ - 1). In the economics section of Montenegrin daily newspapers, there was a significant number of headlines (16) of inappropriate content („Dan“ - 4, „Vijesti“ - 9, „Pobjeda“ - 3). 
A curious feature is that the culture section also includes such headlines, although to a lesser extent, only 8 („Dan“ - 1, „Vijesti“ - 4, „Pobjeda“ - 3). The rest refers to the following sections (,Dan“ - news of the day (3), occasions (2), attitude (3), regions (1), the Balkans (3); Vijesti - columns (6); „Pobjeda“ - current (5), comment (2), chronicle of Podgorica (1), others write (3).

Headlines reveal the attitude, position and message that the author directs to the audience. A critical attitude is sometimes a one-way thing, as a result of the division on us and them, and such a relationship is largely present in many headlines. Bombastic and tendentious headlines and subheadings appear with punctuation interventions, such as quotation marks, which radically changes the meaning of the content (Protest walk on the occasion of May 25, "Milo, does your family know what you're doing to us" (V, May 25); "Walking" officeholders from one ministry to another a threat to the system " (V, May 7); Unacceptable for us to "languish" at position 114 in press freedom (V, May 2); Messages from the Assembly of Trade Union: "Something stinks in the state of Montenegro" (V, May 15).

Another common feature of Montenegrin newspapers are headlines with manipulative punctuation marks - this headline type contains punctuation that can be aimed at boosting the emotional charge and bear deliberate references to "relevant" news (as is the case with an exclamation mark), may indicate the unconfirmed information or disbelief of the author of the text (question mark), or the unfinished thought (ellipsis), leaving room for diverse interpretations and speculation of the readers. (Minister calls us to Podgorica to attach the wire, and what when the season is over? (V, May 16); Do you want electricity or healthy air? (V, May 10); Who was smoking at the expense of the state? (V, May 28); Hey, fatso! (V, May 9); Milo, morals... (V, May 26); Adieu to sanity... (P, May 25); How come Montenegrin women can do it, and Croatian women can not! (P, May 14)).

Deliberate exaggeration and sometimes also inappropriate reporting are a direct product of sensationalism in the media, whose main role thus becomes the attention of readers. The newspapers show an increasing tendency of deliberate "vilification" or ridicule of people, mostly public figures, but also of social occurrences. In Montenegrin media this is evident in the pro-opposition newspapers Vijesti and Dan, and to a lesser extent in the pro-government Pobjeda (Dan - The mafia runs the country (May 11); Milo is panicking (May 13); Prime Minister manipulator (May 13); No one wants to face Milo (May 21); Đukanović family not large in numbers, but in positions (May 11); Linguistic changes, language raped (May 20); 60 thousand wreck cars in Podgorica (May 23); The plant became a concentration camp (May 16); Losers, happy Victory Day (May 12); Discontinue Ustasha pensions (May 20); Vijesti - Danilović: 500 flags for the 500 affairs and profiteers (May 24) HURRAY: DPS painting again (May 24); DPS: Medojevic sounds farcical (May 15); More dynasties in Montenegrin public service than in the history of Europe (May 4); Who of the ministry staff was smoking at the expense of the state? (May 21); „Pobjeda“-Mischief makers scared investors away from the Queen's beach (May 28); The role of the 
Montenegrin Academy of Science and Art: Tradition of destruction. Daydreams. Specialists and Special Forces. Poker or Russian roulette (May 3)).

It is obvious that these newspaper headlines violate ethical codes, to a greater or lesser extent, depending on the editorial policy of the dailies.

It is noted that almost all of the analyzed newspapers have headlines of short or medium length (word, phrase, sentence).

Word - Bellowing (P, May 3);

Syntagm - Disgrace for the country (D, May 2); A game of cat and mouse (D, May 13); Gays and fags (V, May 25);

Sentence - Đuranović shoveling also (D, May 13); One and all against the misunderstood youth (V, May 16); Hoping it won't be a girl (P, May 12);

Sentence sequence - Unclear business of Minister Ivanovic's wife: Instalment exceeds salary (V, May 11); The role of the Montenegrin Academy of Science and Art: Tradition of destruction. Daydreams. Specialists and Special Forces. Poker or Russian roulette (P, May 3).

Authors often begin their headlines with the names of individual politicians or parties followed by their statements, and even with whole sentences („Vijesti“, „Pobjeda"). This parceled nominal unit is structurally followed by a punctuation break (colon) and then by a complement sentence. The nominative form of the noun is not structurally dependent on the second part of the headline that bears the informative brunt of the sentence. Using such a headline, a reporter can very effectively express an opinion, attitude, statement of the parceled unit, emphasizing the informatively more important content of the information in the second part of the headline. In these cases, we at times note the occurrence of longer comments that are unsuitable for headline function due to their length.

„Vijesti“" - Calovic: I am not afraid of the underworld which Djukanović belongs to (May 12); Ivanovic is still quiet: Who was smoking at the expense of the state? (May 28); Vucinic: The ironworks people were killed and injured, just like on a battlefield (May 8); Misolic: I could have cut her hair a little bit, but you wouldn't let me (May 8);

„Pobjeda“ - Djukanović: We are enduring the coalition with SDP solely because of NATO (May 12); North Korea: Minister executed? (May 14). While comparing (in percentage) only the editorial policies of the dailies and their conceptions, we can largely rely on the headline type which an individual newspaper prefers. During this brief period, we note that most of sensationalist headlines appear in the Vijesti (25\%), followed by those in the „Dan“ $(17 \%)$, and the least of these were recorded in the "Pobjeda“ (12\%). On the other hand, informative headlines were mostly recorded in the „Pobjeda“ (40\%), followed by the Dan (34\%), and the least in the „Vijesti“" $(27 \%)$. As for combined headlines, the numbers are approximately the same in all three dailies (D - 38\%, P - 36\%, V - 35\%), and it is similar with metaphorical 
headlines (D - 11\%, V - 13\%, P - 12\%). We can see that there are different approaches to headlines, which is understandable because one of these newspapers is printed for the purposes of the government, while the other two dailies are pro-opposition.

Another parameter indicating the headline culture of individual newspapers and their reporting orientation is, of course, the motive for a certain text. Thus, in our analysis we have noticed a large number of headlines referring to an actual event, while fewer headlines dealt with pseudo-events. As is well known in the daily newspapers, in addition to the texts written on the basis of press statements, we often see texts containing the statements of one or the other party - position, opposition, and sometimes both. Such statements are often found on the front pages also. Most of these headlines come from Vijesti - 12, and much less from „Pobjeda“, only 2 headlines.

In the case of Montenegrin daily newspapers, according to the number of press releases and statements of political actors in the headlines, we notice that there is no party that is predominantly present. However, in the opposition newspapers Dan and Vijesti, but also in the pro-government Pobjeda, more attention is given to the state authorities and the ruling coalition, with fewer headlines addressed to the opposition parties and NGOs.

We note that in one Montenegrin daily newspaper (,Vijesti“), headlines of inappropriate content appear: It is a sad country in which prime minister engages in sex scandals (May 12); Porno Negro (May 16); ZIKS: A convict cut off his sex organ in the bathroom (May 14); Paupers, $f^{*}$ ck you (May 20).

A headline is an important segment of the media, but it is unethical to present facts in this manner. It is obvious that the lack of journalistic ethics for the readers and a tendency for provocation induces editors to walk the line of good and appropriate taste.

\section{SENSATIONALISM IN THE HEADLINES}

Headlines in Montenegrin daily newspapers are marked with sensationalism and political colors, so that basic principles of professionalism and impartiality are sometimes called into question. They may be the result of commercial objectives, political ambitions. Nowadays, Montenegrin readers want interactive, interesting forms that do not take much time for consuming.

Sensationalism attracts audiences, opens the door for new advertisers, and affects the profit growth of the media that offers it. If we bear in mind that in today's consumer society only the best survive, it is somewhat more under-standable why media shift towards favorizing offers of commercial content and tabloid journalism that the global market is increasingly demanding (Vlahovic and Olujic, 2010, p. 149). 
Focusing the attention of readers to a specific text is an extremely important segment of journalistic work. It becomes crucial at the moment when a reader is deciding whether to continue reading a certain text. This principle of ,playing“ with a reader's glance can be a walk on the edge of journalistic professionalism, as a journalist will consciously strive to place in a headline as attractive information as possible, sometimes without regard either for context or accuracy. Playing with the attention of the readership is often an introduction to various types of journalistic manipulation. Headlines make stronger impression on the readers than texts do, and sometimes they are the only information and orientation for the readers. The type of a newspaper (serious, half-tabloid and tabloid) determines the „strength" of a headline, and in the „race“ for sales, ethical principles are forgotten not only in tabloids, but also in other newspapers. The so-called quality newspapers will put the information before the attraction in their headlines, though even responsible journalists try to find a way to combine these two requirements. Such combinations go to prove the talent of such journalists, but also their awareness of the fact that headlines ,sell newspapers" (Rus-Mol and Zagorac-Kerser, 2005, p. 150).

The goal of every sensational reporting is to increase the reading of a newspaper, resulting in the shift of focus from objective journalism toward those "striking" aspects of stories that attract a larger share of a wider audience (Campbell, 2009, p. 9). As is known, the primary task is to inform readers, to sell as many copies, but also to attract as many advertisers as possible. The larger the number of readers of Montenegrin headlines, the greater the interest of advertisers, inevitably resulting in higher profits for the publishers. Headline sensation thus becomes a journalistic style rooted in the nature of news. They are intended, in part, to wake up, excite, and regardless of ,the topic being a political scandal or a double murder - to shock the public" (Stephens, 1998, p. 2).

Changes in the headlines of Montenegrin newspapers will depend on various factors, primarily on editorial policy, selection of topics, and these will reflect the main focus and the message sent to the readers from the newsrooms. Headlines are the most common place for editorial interventions. In this aspect, the question arises of headline ethics, namely, the effects that such messages can cause. For the selection of a topic in Montenegrin media, it is not only the informational value that is crucial, but also the political significance of its publication (or non-publication), and such selection criteria are used to achieve a particular propaganda objective.

Selecting a headline in Montenegrin daily newspapers is under the influence of two hidden, but extremely crucial features - value and significance. The value of news is essential for the relationship between the information source and the journalist who used it and stands for it, while significance is crucial for the relation between journalists and the media audience with which they communicate directly (Jergović and Raguz, 2014, p. 38). While reporting, media workers „consciously or subconsciously participate in the selection, highlight certain events and news, while ignoring 
others. In this process, media help in determining the prevailing beliefs, assumptions and values in a society“ (Kanizaj, 2004, p. 32).

"Sensationalist headlines also relate to the measurement of two values - one that a message actually carries in its content and the value that is offered to the reader in the headline" (Bobic, 1987, p. 59). According to this author, if the two values are balanced, sensationalism should not be present. However, if a headline clearly suggests a biased content of the text, sensationalism is indicated (ibid, 59). Sensationalism is actually ,event inflation“, and in cases where it is present, it strives to attract the attention of readers (ibid, 44). In Montenegrin headlines, this attention is achieved specifically by using sensational headlines, trivialization, unusual examples.

Headlines in the analyzed corpus often balance on the edge of comfort, privacy, but are also susceptive, inviting, ticklish and basically competent. They go beyond the threshold of public morality, and sometimes even into the abyss of sensationalism and mediocrity. The increase of sensationalism in the headlines of some daily newspapers in the test corpus is the result of intensified commercial activities of the newspapers in which information becomes a commodity to be sold as soon and as well as possible. Due to the conditions dictated by the market, and in order to survive, the owners and editors of newspapers devote more and more space to headlines of sensational character.

\section{CONCLUSION}

If, as the rules for marketing-based news production, we take searching for images rather than ideas, avoiding complexity, exaggeration if necessary to gain attraction, avoiding extensive production of the news, then the media coverage of headlines in Montenegrin daily papers during the month of May, 2015, can be described as news production for sale.

Montenegrin newspapers do not have same editorial policies, but must respect the same basic principles of journalistic profession: truthfulness, honesty, accuracy, balance and fairness. Sometimes it takes only a glance at the front pages of Montenegrin daily newspapers and you already have a picture of the media in Montenegro. The headline of each text represents its mirror, or at least that is how it should be. A certain degree of that which is sensationalist and tabloid can be noticed in headlines of the analyzed daily newspapers. When treatment of an event is based on emotion rather than facts, this goes in favor of market logic and attitude towards what the audience is reading. Headlines are motivated by circulation reasons, rating, but also by recognition that the media create the reality in the interests of particular politics. It is evident that in almost all the newspapers negative titles are highlighted and considered "better" than the positive and good ones. We also note that the consi- 
derably shortened texts, which should not be demanding for the reader, are published under striking headlines.

After taking into account the number of sensationalist headlines published in the analyzed newspapers, which are mainly related to the government, we find a confirmation of the hypothesis that communication culture is at a lower level than expected. The hypotheses that the majority of these headlines occur in sections on interior politics and society, and that there are certain differences in preference of content in the headlines of Montenegrin daily newspaper, have also been confirmed. The fact that politics take the main place in Montenegrin newspapers indicates the understanding of the politics, its importance for everyday life, but is also one of the signs of politicization of these dailies.

In the analyzed sample, it has been noted that headlines often emphasize attractiveness rather than informativeness, that newspapers have different editorial policies (increasing tabloidization), different designs (with long or short headlines).

A headline, being the strong position of the text, is the bearer of meaning. As an independent part, it primarily has the function to interest and attract the attention of the readers, who will get basic information as soon as they read the headline, and thus will continue reading the text or give up on it. Editors are aware that provocative and eye-catching headlines are the best for attracting readers. It should be noted that each sensationalist headline has a greater impact on us than a positive one, the simple reason being that we remember bad events more easily than good ones. In newspapers, we can often read headlines that are at their core characteristic informational - impartial, but carry negative connotations or invite the reader to read between the lines.

Media culture, as a part of general culture, is the introduction of order in social life, that is, in a public field. It consists of values, convictions, beliefs, attitudes, symbols, styles and patterns of action and behavior of individuals and society. Although the study included only a small sample of headlines in Montenegrin daily papers, the results are certainly indicative of thinking about media headline culture, since the media are mediators in social and cultural system of each country.

\section{LITERATURE}

Bobic, D. (1987), What about the event?, IRO „Informator”, Zagreb.

Breton, P. (2000) The Manipulated Word, Clio, Belgrade (in Serbian).

Campbell, J. (2009), Yellow Journalism: Puncturing the Myths Defining the Legacies, Praeger, Westport.

Jergovic, B., Raguz, A. (2012), „How important is science in Croatian daily newspapers? Analysis of articles published in 2012 in Jutarnji list, Večernji list, Slobodna Dalmacija and Novi list", Media studies, Vol. 5, No. 10, pp. 36-50 (in Croatian). 
Kanizaj, I. (2004), „Representation of National Minorities in Croatian Daily Newspapers - A Comparative Review 2001-2003“, Political thought, Vol. 16, No. 2, pp. 30-46 (in Croatian).

Katnic-Bakarsic, M. (1999), Linguistic stylistics, Open Society Institute, Center for Publishing Development, Electronic Publishing Program, Budapest (in Hungarian).

Katnic-Bakarsic, M. (2012), Between the discourse of power and the power of discourse, Naklada Zoro, Zagreb (in Croatian).

Malovic, S. (2007), Credibility of Newspapers, University Bookstore, Zagreb (in Croatian).

McLuhan, M. (1964), Understanding Media: The Extensions of Man, New York.

Perovic, S. (2009), Language in action, CID, Podgorica (in Serbian).

Potter, J. (2011), Media Literacy, Clio, Belgrade (in Serbian).

Rus-Mol, S; Zagorac-Keršer, A. J. (2005), Journalism, Clio, Belgrade.

Stephens, M. (1998), A History of News, Viking Penguin, New York.

Susnjic, Dj. (1984), Fishermen of human souls, Youth, Belgrade (in serbian).

Vlahovic, T., Olujić, Z. (2010), „Media and Corporate Social Responsibility: A Global Context", Media Dialogues, Vol. 3, No. 7, pp. 147-155.

Tasic, S. http://www.fairpress.eu/me/blog/2014/10/16/

Tosovic, B. (2002), Functional styles, Institut für Slawistik der Karl-FranzensUniversität Graz.

Udovicic, R. (2007, Informants with different goals, Media plan institut, Sarajevo. 